\title{
Analysis of effects of stimulation in vitro of ovalbumin primed lymph node cells on adoptive transfer of experimental immune mediated blepharoconjunctivitis in Lewis rats
}

Hironori Yoshida, Osamu Yoshida, Hiroshi Iwamoto, Koji Nishino, Masatsugu Hashida, Atsuki Fukushima, Hisayuki Ueno

\begin{abstract}
Aim-To analyse the role of stimulation in vitro of lymphocytes on the augmentation of experimental immune mediated blepharoconjunctivitis (EC, formerly EAC) in Lewis rats induced by adoptive transfer.

Methods-Two weeks after immunisation with ovalbumin (OVA), rat draining lymph nodes were collected and $50 \times 10^{6}$ cells were injected into naive syngeneic recipients either directly or after culture in vitro with OVA, concanavalin A (Con A), or purified protein derivative (PPD) for 3 days. Four days after injection the rats were topically challenged with OVA. 24 hours later, they were sacrificed and eyes and spleens were harvested for histology and proliferation assay. In some experiments, naive recipient rats were irradiated with $7 \mathrm{~Gy} \gamma$ ray before transfer. The expression of adhesion molecules and cytokine profile of OVA primed lymph node cells were also investigated.
\end{abstract}

Results-Both infiltrated cell number and splenocyte proliferation in the recipients of stimulated cells were higher than those of unstimulated cells. In vitro stimulation with OVA or Con A induced a severe cellular infiltration, while stimulation with PPD did not. Irradiation markedly diminished cellular infiltration. Stimulation in vitro upregulated the CD4/CD8 ratio by four times and augmented expression of CD25, I-A, ICAM-1 molecules on OVA primed lymph node cells by about five times. IFN- $\gamma$ was detected in OVA primed cells by stimulation in vitro, while IL-4 mRNA was extinguished by stimulation in vitro.

Conclusions-Augmentation of EC by stimulation in vitro of transferred lymphocytes might depend on the upregulation of expression of cell surface molecules and cytokine shift as well as augmented antigen specificity. (Br f Ophthalmol 1998;82:1189-1194)

We previously reported ${ }^{1}$ that ovalbumin (OVA) primed lymph node cells but not OVA primed sera were able to adoptively transfer experimental immune mediated blepharoconjunctivitis (EC, formerly EAC) in Lewis rats. We also demonstrated that stimulation in vitro of OVA primed lymph node cells augmented the infiltration of inflammatory cells into the conjunctiva. Stimulation in vitro of lymphocytes has been demonstrated to transfer their function efficiently not only in our system but also in many other systems such as experimental autoimmune encephalomyelitis (EAE), ${ }^{23}$ experimental autoimmune uveitis (EAU), ${ }^{45}$ or experimental lens induced uveitis. ${ }^{6}$ Although several factors such as adhesion molecules were identified to be involved in augmentation of the disease transfer by stimulation in vitro of lymphocytes, the mechanism of this augmentation has not been fully elucidated.

We can easily imagine that stimulation in vitro of lymphocytes with antigens augments the ability of transferred lymphocytes to gather at the inflammatory sites, probably as a result of upregulation of the affinity of transferred lymphocytes with the antigen which exists at the inflammatory sites. Although the number of inflammatory cells in the conjunctiva of rats with EC was increased by stimulation in vitro, infiltrated cells in the conjunctiva were not identified to be from transferred cells, recipient's cells, or a combination of both. The first question is whether the increased number of inflammatory cells at the site is due to only infiltration of transferred cells or partially to cells from recipients together with transferred cells.

In EAU or EAE, the adoptive transfer of cells stimulated with either concanavalin A (Con A) or disease related antigens induced the disease, while in other systems such as experimental lens induced uveitis models, the transfer of Con A stimulated cells were unable to induce the disease ${ }^{6}$ (and unpublished data). This information indicated that both the level of activation and antigen specificity are important for the induction of diseases, and that the degree of involvement of each factor seems to depend on the nature of diseases. Therefore, we compared three stimulants, OVA, Con A, and purified protein derivative (PPD) for their ability to induce EC on stimulation of OVA primed lymph node cells.

Stimulation of lymphocytes in vitro changes various characters of lymphocytes. Variables which we usually regard as the activated state of cells include cell surface molecules, ${ }^{7-10}$ cytokine production, cell proliferation, ${ }^{11-13}$ and so on. Cell surface molecules such as CD25 or CD69 are known as activation markers ${ }^{14}$ and 
cell adhesion molecules such as LFA- $1^{15}$ are also upregulated during stimulation in vitro. These adhesion molecules are regarded as important for homing and invading of cells into target tissues. The next question is what are the changes in the expression of cell surface molecules, probably related to augmentation of inflammation, detected in stimulated cells compared with unstimulated cells?

Other important changes seen during stimulation in vitro are cellular proliferation and cytokine production. ${ }^{11-13}$ It has been revealed in many experimental systems that IFN- $\gamma^{16}{ }^{17}$ is a tissue destructive factor compared with IL- $4,{ }^{18}{ }^{19}$ which is called an immunoregulatory cytokine. In general, allergic diseases are mediated by $\operatorname{IgE}$ and the $\operatorname{IgE}$ production is promoted by IL- 4 and inhibited by IFN- $\gamma{ }^{20}$ On the other hand, EC in Lewis rats exhibited a dominant involvement of cellular immunity but not humoral immunity in both induction and effector phases. ${ }^{1}$ The last question is to determine cytokines related to the development of EC by testing changes of cytokine profiles of OVA primed lymph node cells by stimulation in vitro.

\section{Materials and methods}

RATS

Six to 8 week old male Lewis rats were purchased from a commercial source (Seac Yoshitomi, Fukuoka, Japan) and maintained in a specific pathogen free animal facility at Kochi Medical School. All animal procedures conformed with institutional guidelines and the ARVO Resolution on Use of Animals in Research.

IMMUNISATION

Rats were injected with $100 \mu \mathrm{g}$ of ovalbumin (OVA, grade V, Sigma Immunochemicals, $\mathrm{St}$ Louis, MO, USA) emulsified with complete Freund's adjuvant (CFA, Yatoron, Tokyo, Japan) to a final volume of $100 \mu \mathrm{l}$ in their left hind footpads. In some experiments, rats were immunised with only CFA without any antigens.

ADOPTIVE TRANSFER OF DISEASE

Methods have been described previously. ${ }^{1}$ In brief, cells from immune inguinal lymph nodes were harvested 14 days after immunisation, teased, and washed three times with RPMI1640 medium (Mediatech, Herndon, VA, USA) supplemented with L glutamine ( $2 \mathrm{mM})$, penicillin $(100 \mathrm{U} / \mathrm{ml})$, and streptomycin (100 $\mu \mathrm{g} / \mathrm{ml}$ ). After washing, naive recipients received $50 \times 10^{6}$ fresh unstimulated cells by intravenous injection in the dorsal penile vein. The remainder of the cells was stimulated at the concentration of $10^{7}$ cells $/ \mathrm{ml}$ with $50 \mu \mathrm{g} / \mathrm{ml}$ of OVA in the medium containing $5 \times 10^{-5} \mathrm{M}$ 2-mercaptoethanol (2-ME) and 10\% fetal calf serum (FCS, ICN Biomedical Japan Co, Tokyo, Japan). In some experiments, cells were stimulated with $1 \mu \mathrm{g} / \mathrm{ml}$ of concanavalin A (Con A, Sigma Immunochemicals, St Louis, MO, USA) or protein purified derivative (PPD, Japan BCG, Tokyo, Japan) at $10 \mu \mathrm{g} / \mathrm{ml}$ instead of OVA. Three days later, culture supernatants were harvested and used for cytokine ELISA. Then $50 \times 10^{6}$ stimulated cells were injected intravenously into the syngeneic recipients. Four days after transfer, the recipients were challenged with OVA by eye drops. Eyes and spleens were harvested 24 hours after challenge for histology and proliferative responses respectively. The disease was evaluated by the number of infiltrated cells per field detailed in Fukushima et al. ${ }^{1}$

PROLIFERATION ASSAY

Spleens from recipient rats were combined by group and experiments were repeated as recorded. Lymphocyte proliferation assay was set up in quadruplicate in a 96 well flat bottom plate. Splenocytes $\left(3 \times 10^{5}\right.$ cells/well $)$ were cultured in $0.2 \mathrm{ml}$ final volume of the RPMI-1640 medium supplemented with $5 \%$ FCS, $2-\mathrm{ME}$ $\left(5 \times 10^{-5} \mathrm{M}\right)$, L glutamine $(2 \mathrm{mM})$, penicillin $(100 \mathrm{U} / \mathrm{ml})$, and streptomycin $(100 \mu \mathrm{g} / \mathrm{ml})$. Cells were stimulated with OVA at the final concentration of $0.1,1,10$, and $100 \mu \mathrm{g} / \mathrm{ml}$ each. They were also stimulated with Con $\mathrm{A}$ at $1 \mu \mathrm{g} / \mathrm{ml}$ or with PPD at $10 \mu \mathrm{g} / \mathrm{ml}$. After incubation for 72 hours at $37^{\circ} \mathrm{C}$ in a humidified atmosphere with $5 \%$ carbon dioxide, cultures were pulsed for 16 hours with $0.5 \mu \mathrm{Ci} /$ well of ${ }^{3} \mathrm{H}$ thymidine (Japan Atomic Energy Research Institute, Tokai, Japan). Cultures were then harvested and the radioactivity was measured by the standard technique. Data were expressed as stimulation indices.

IRRADIATION OF RECIPIENT RATS

Recipient rats were irradiated with a dose of 7 Gy using a gamma irradiator 1 day before adoptive transfer.

FLOW CYTOMETRIC ANALYSIS

Either stimulated or unstimulated cells were stained with the following anti-rat antibodies. Anti-CD4 and anti-CD8 (Pharmingen, San Diego, CA, USA) were FITC labelled. AntiCD 3 and anti-CD25 (Pharmingen, San Diego, CA, USA), anti-I-A (OX-3), and antiCD45RA (OX-33) (Serotec, Oxford), antiCD11a (LFA-1 $\alpha$ ), and anti-CD54 (ICAM-1) (Caltag Laboratories, Burlingame, CA, USA) were biotin labelled. The cells were incubated for 45 minutes on ice with the primary antibodies mentioned above $\left(0.08-2 \mu \mathrm{g} / 2 \times 10^{6}\right.$ cells) and washed with cold 5\% FCS-PBS. Streptavidin-PE (Pharmingen, San Diego, CA, USA) was added to the cells stained with biotin conjugated antibodies for 10 minutes and the cells were washed again. Then the cells were analysed using FACscan (Becton Dickinson, Mountain View, CA).

CYTOKINE ELISA USING CULTURE SUPERNATANT Lymph nodes from three to eight OVA primed rats were combined for culture. Culture supernatants were harvested at the end of culture before the adoptive transfer mentioned in the section "adoptive transfer of disease". They were assayed by commercial cytokine ELISA (BioSource International, Camarillo, CA, USA) for IFN- $\gamma$ concentrations strictly following the recommended method. 
Table 1 Sequences of primers of rat cytokines and $\beta$ actin

\begin{tabular}{|c|c|c|c|}
\hline \multirow[b]{2}{*}{$m R N A$} & Sense primer & Antisense primer & \multirow{2}{*}{$\begin{array}{l}P C R \\
\text { product } \\
\text { size }\end{array}$} \\
\hline & $5^{\prime}$ & $5^{\prime}$ & \\
\hline$\beta$ actin & TTGTAACCAACTGGGACGATATGG & GATCTTGATCTTCATGGTGCTAGG & 759 \\
\hline IL-2 & CAAAGGAAACACAGCAGCACCTGG & TCCTCAGAAATTCCACCACAGTTG & 342 \\
\hline IL-4 & TGATGGGTCTCAGCCCCCACCTTGC & CTTTCAGTGTTGTGAGCGTGGACTC & 378 \\
\hline IL-10 & TCAGCACTGCTATGTTGCCTGCTC & GAGTGTCACGTAGGCTTCTATGC & 512 \\
\hline IFN- $\gamma$ & ATCTGGAGGAACTGGCAAAAGGACG & CCTTAGGCTAGATTCTGGTGACAGC & 288 \\
\hline
\end{tabular}

RT-PCR ANALYSIS OF CYTOKINES

Fresh lymph node cells or stimulated lymph node cells before the adoptive transfer were used. Cellular RNA was isolated by acid/ guanidine isothiocyanate/phenol/chloroform extraction. ${ }^{21}$ RNA was transcribed into cDNA in a $20 \mu \mathrm{l}$ reaction mixture containing $1 \mu \mathrm{g}$ of total RNA. A cDNA equivalent to $1 \mu \mathrm{g}$ of total RNA was amplified in a $100 \mu \mathrm{l}$ reaction mixture containing $250 \mu \mathrm{M}$ of dNTP, $0.2 \mu \mathrm{M}$ of the primer pair, $8 \mu \mathrm{l}$ of a 10 -fold dilution of PCR buffer, and 2.5 U of Taq DNA polymerase (Perkin-Elmer/Cetus, Emeryville, CA, USA). The sense and antisense primer sequences derived from rat IL-2, IL-4, IL-10, IFN- $\gamma$, and $\beta$ actin cDNA are summarised in Table 1. PCR was performed on a DNA thermal cycler (Perkin Elmer, Foster City, CA, USA) for 30 cycles $\left(94^{\circ} \mathrm{C}\right.$ for 30 seconds, $51^{\circ} \mathrm{C}$
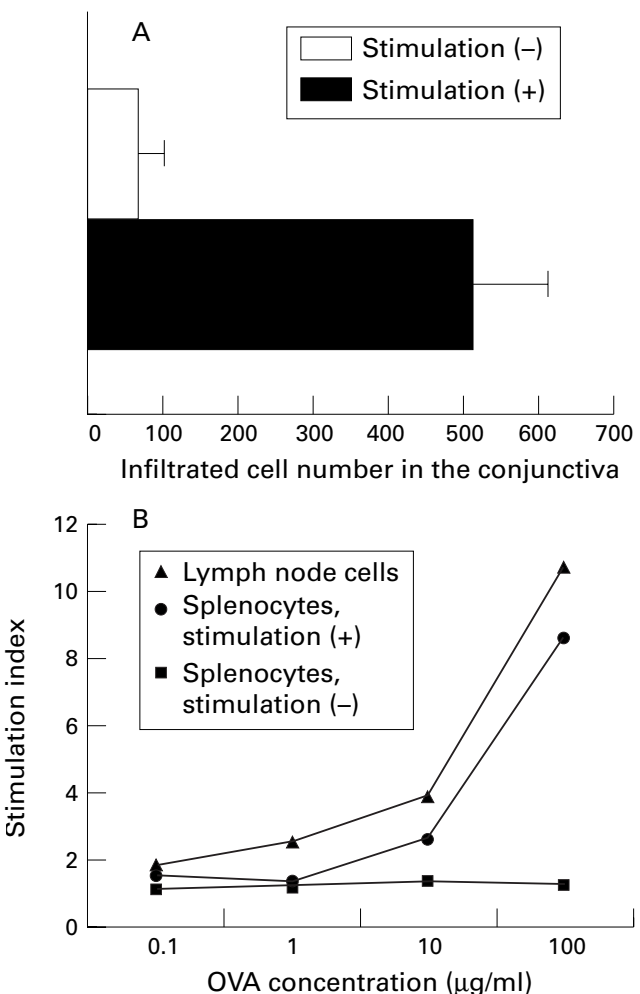

Figure 1 (A) Infiltrated cell number in the conjunctival fornix of recipients of OVA primed cells $\left(50 \times 10^{6}\right)$ either stimulated in vitro or not. $X$ axis indicates the mean number of infiltrated cells of three rats. Error bars indicated standard deviations. (B) Proliferative responses of lymph node cells from donor or spleen cells from recipients transferred with OVA primed lymph node cells either stimulated in vitro or not. Data are means of SI values of three rats of each group. Similar results were obtained in two more separate experiments. The combined mean cpm values in the unstimulated control cultures of rats were: donor's lymph node cells: 470 (43), recipient's splenocytes with stimulation in vitro: 3321 (166), recipient's splenocytes without stimulation in vitro: 3301 (104). for 30 seconds, and $72^{\circ} \mathrm{C}$ for 1.5 minutes). The PCR products were electrophoresed in $3 \%$ agarose gels and visualised with ultraviolet light. The molecular size marker used in this study was $\phi$ X174/ Hae III digest (Wako, Osaka, Japan).

STATISTICAL ANALYSIS

Statistical comparison of the number of infiltrated cells between two groups was performed using Student's $t$ test.

\section{Results}

STIMULATION IN VITRO AUGMENTS THE NUMBER OF INFILTRATED CELLS IN THE CONJUNCTIVA Figure 1A shows the number of infiltrated cells in the conjunctiva of the recipients of OVA primed lymph node cells either with or without stimulation in vitro as described in the Materials and methods. Stimulation in vitro with OVA increased the number of infiltrated cells (stimulated cells: 512.3, unstimulated cells: $45.2)$ by 12 times $(\mathrm{p}<0.001)$. In addition, although splenocytes from the recipients of stimulated cells showed lower responses to OVA compared with the OVA primed lymph node cells, they exhibited higher proliferative responses to OVA than those of the recipients of fresh cells (Fig 1B). These results indicated that stimulation in vitro efficiently augmented the adoptive transfer of EC and cellular immunity.

ANTIGEN SPECIFIC PRIMING AND STIMULATION IN VITRO ARE IMPORTANT FOR EFFICIENT ADOPTIVE TRANSFER OF EC

To rule out the possibility that EC induced by the adoptive transfer of cells does not depend on the antigen specific reaction, we set up two experiments. Firstly, we transferred primed lymph node cells from rats injected with only CFA to demonstrate the essential role of antigen specific priming in inducing EC. We also compared the stimulants on OVA primed cells to investigate the role of antigen specific stimulation in vitro in the adoptive transfer of EC. The transfer of in vitro stimulated lymph node cells from rats injected with only CFA did not

Table 2 Comparison of stimulants for adoptive transfer of $E C, I F N-\gamma$ production, and cellular proliferation

\begin{tabular}{llll}
\hline & OVA & Con $A$ & PPD \\
\hline Infiltrated cell number & 145.3 & 118.3 & 6.5 \\
$\quad(S D)^{\star}$ & $(49.1)$ & $(12.4)$ & $(1.4)$ \\
IFN- $\gamma$ production $\dagger$ & 1884 & 7831 & 2012 \\
Cellular proliferation $\neq$ & 11.2 & 46.1 & 9.6 \\
\hline
\end{tabular}

^Infiltrated cells per field were counted in the palpebral conjunctiva.

†The amount of IFN- $\gamma$ in the culture supernatant $(\mathrm{pg} / \mathrm{ml})$. $\ddagger$ Data were recorded as stimulation index. 
Table 3 Flow cytometric analysis of OVA primed lymph node cells

\begin{tabular}{|c|c|c|c|c|c|c|c|c|}
\hline & \multicolumn{2}{|l|}{$C D 25$} & \multicolumn{2}{|l|}{$I-A$} & \multicolumn{2}{|l|}{$L F A-1$} & \multicolumn{2}{|l|}{$I C A M-1$} \\
\hline & $\%$ positive* & MFIt & $\%$ positive & $M F I$ & $\%$ positive & $M F I$ & $\%$ positive & $M F I$ \\
\hline Before stimulation in vitro & 6.7 & 52.5 & 26.1 & 444.6 & 97.7 & 50.2 & 4.4 & 43.5 \\
\hline After stimulation in vitro & 36.3 & 132.4 & 24.4 & 2319.8 & 95.3 & 50.9 & 22.3 & 46.9 \\
\hline
\end{tabular}

$\star \%$ positive $=$ percentage of cells expressing the molecule in all cells.

$\dagger \mathrm{MFI}=$ mean fluorescence intensity of positive cells.

induce any cellular infiltration into the conjunctiva of the recipient rats challenged with OVA (data not shown). Inflammatory cell infiltration was not detected in the conjunctiva of the recipients of OVA primed lymph node cells stimulated with PPD at $10 \mu \mathrm{g} / \mathrm{ml}$. The proliferative response of OVA primed lymph node cells for PPD at $10 \mu \mathrm{g} / \mathrm{ml}$ is almost equal to that of OVA at $100 \mu \mathrm{g} / \mathrm{ml}$ (Table 2). There were no remarkable differences in the number of infiltrated cells in the conjunctiva between the recipients of cells stimulated with OVA and those with Con A (average infiltrated cell number; OVA $=145.3$, Con $\mathrm{A}=118.3$ ) (Table 2).

NOT ONLY STIMULATED DONOR CELLS BUT ALSO CELLS FROM RECIPIENTS GATHER AT THE INFLAMMATORY SITE

We tested whether donor cells merely infiltrated into the inflammatory sites or triggered inflammation and promoted the gathering of recipients' cells at the inflammatory sites. We irradiated the recipients 1 day before the adoptive transfer to deplete haematopoietic cells in the recipients. No apparent histological changes in the conjunctiva of irradiated rats were observed by the routine histological study using haematoxylin and eosin staining. As shown in Figure 2, irradiation drastically reduced the number of infiltrated cells in the conjunctiva (the average number of infiltrated cells of the recipients without irradiation $=$ 306.1; that with irradiation $=56.2)(\mathrm{p}<0.001)$. Taking the data of Figure 1A into consideration, it can be interpreted that stimulation in vitro augmented not only the homing ability of donor cells but also the ability of inducing recipient cells in the conjunctiva.

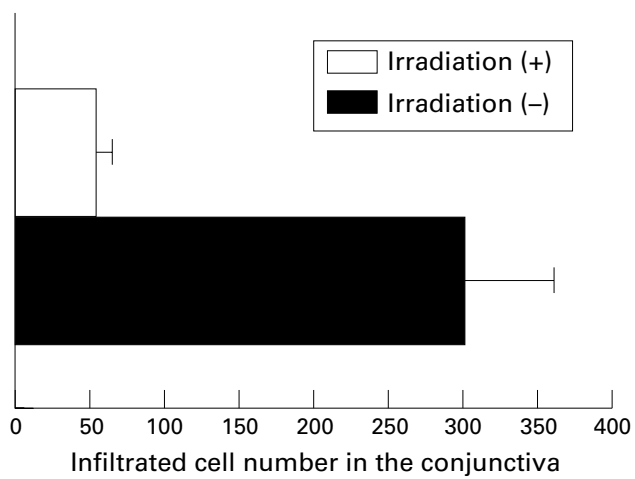

Figure 2 Infiltrated cell number in the conjunctival fornix of recipients either irradiated or not. All recipients received $50 \times 10^{6}$ stimulated OVA primed lymph node cells. $X$ axis indicates the mean number of infiltrated cells per field of three rats in each group. Error bars indicated standard deviations.
PHENOTYPIC CHANGES OF TRANSFERRED CELLS BY IN VITRO STIMULATION

To test the changes of cell surface markers on the cells after stimulation in vitro compared with cells before stimulation, FACscan analysis was performed. The percentage of the total number of cells, which was based on the same form of side scatter-forward scatter profile, and mean fluorescence intensity (MFI) of positive cells was indicated. Although the T/B ratio (before stimulation: $76.7 \% / 19.4 \%$, after stimulation: $79.2 \% / 16.7 \%$ ) was not changed, the CD4/CD8 (before stimulation: $56.1 \% / 24.9 \%$, after stimulation: $57.0 \% / 6.8 \%$ ) ratio was increased dramatically by stimulation in vitro with OVA. Percentage positive cells and/or mean fluorescence intensity of positive cells concerning CD25, I-A and ICAM-1 molecules were increased (Table 3).

COMPARISON OF STIMULANTS ON PRODUCTION OF IFN- $\gamma$ BY OVA PRIMED LYMPH NODE CELLS To compare three stimulants (OVA, Con A, and PPD) for IFN- $\gamma$ production of OVA primed lymph node cells, ELISA was performed using culture supernatants. In parallel with the cellular proliferation, Con A stimulated cells produced IFN- $\gamma$ four times more than OVA stimulated cells, while PPD stimulated cells produced almost as much IFN- $\gamma$ as that of OVA stimulated cells (Table 2).

\section{IL-4 MRNA WAS EXTINGUISHED BY STIMULATION} IN VITRO

By cytokine ELISA, we were able to see only the production of cytokine after stimulation in vitro. To compare the cytokine RNA from cells before stimulation in vitro with that after stimulation, RT-PCR using RNA from cells either before or after stimulation was carried out. As shown in Figure 3, a marginal IL-4 and IL-2 signal was obtained in cells that were not stimulated, whereas stimulation resulted in the absence of the IL- 4 signal and a small increase in the IL-2 signal. IL-10 and IFN- $\gamma$ were detected in both samples.

\section{Discussion}

While IgE mediated immune responses are known to be the major effector mechanism for allergic conjunctivitis, cellular immunity is also considered to be involved in the induction of certain types of allergic conjunctivitis such as vernal keratoconjunctivitis. ${ }^{22}$ To clarify the involvement of cellular immunity in the development of allergic conjunctivitis, we established EC in Lewis rats by either active or passive immunisation. ${ }^{1}$ The purpose of this study is to further investigate the mechanisms by which EC is induced by passive immunisation. 
Before stimulation

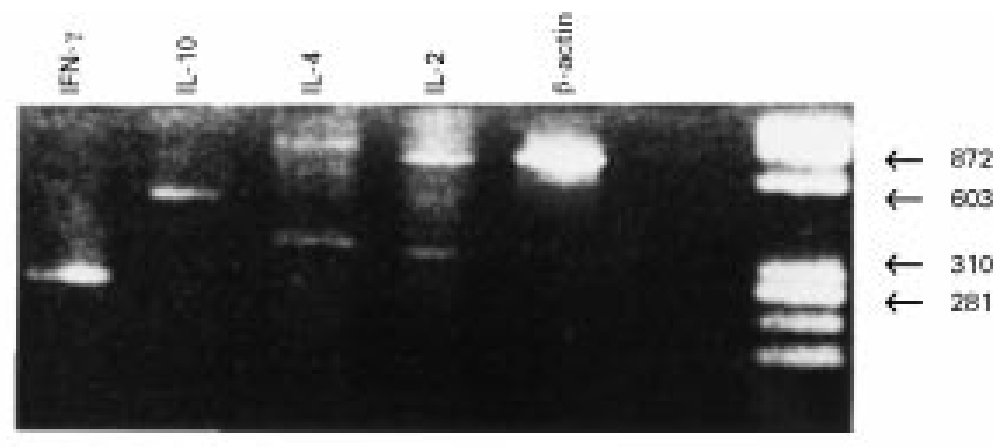

After stimuletion

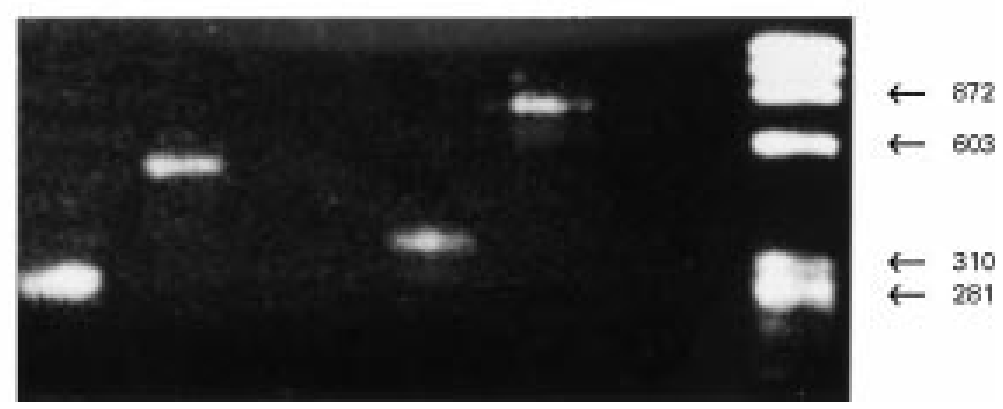

Figure 3 RT-PCR of RNA extracted cells either before or after stimulation in vitro. RT-PCR was performed as in Materials and methods. Primers used were rat IL-2,IL-4, IL-10,IFN- $\gamma$, and $\beta$ actin. PCR products were electrophoresed in 3\% agarose gels and visualised with ultraviolet light.

Haematoxylin and eosin staining of the recipients' conjunctiva demonstrated that mononuclear cells predominantly infiltrated into the conjunctiva to cause inflammation. Although we did not perform immunohistochemical staining such as CD4 cell surface marker, few plasma cells were detected. In addition, we demonstrated that the transfer of $\mathrm{CD} 4^{+} \mathrm{T}$ cell line specific for OVA peptide 323 339 induced EC (submitted for publication). In keeping with our previous report that EC could not be transferred by OVA primed serum, not humoral immunity but cellular immunity is essential for the induction and development of EC in our system.

The data from Figure 1A and Figure 2 may be interpreted to show that the inflammatory cells were composed of both donor cells and cells from recipients. Concerning the mechanism of infiltration of cells from the recipients, it is possible that stimulated cells release some chemoattractant factors to induce cellular infiltration of cells from the recipients. It is also possible that stimulated cells destroy conjunctival vasculature more effectively than unstimulated ones, thus inducing a massive leakage of recipient cells.

Stimulation of cells in vitro with antigen is believed to augment the antigen specificity and function of the cells. To investigate the importance of antigen specificity, antigens were compared for their ability to induce EC. The failure to induce EC by CFA immunisation indicated that antigen specific priming is at least necessary for the induction of EC. Similar to data reported in EAU, mitogenic stimulation as well as antigen specific stimulation induced EC. Although Con A stimulated cells proliferated most vigorously and produced the largest amount of IFN- $\gamma$ compared with other two stimulants, the intensity of the disease induced by Con A stimulated cells was slightly milder than that by OVA stimulated cells. These results suggest that antigen specific activation is important for the transfer of EC and an extensive non-specific mitogenic stimulation can compensate the transfer of EC for the antigen specific activation.

The increase of $\mathrm{CD} 4 / 8$ ratio indicated that our culture condition tends to increase $\mathrm{CD} 4^{+}$ $\mathrm{T}$ cells relatively, which probably work as effector cells in EC, thus leading to augmentation of EC. As the $\mathrm{T} / \mathrm{B}$ ratio and $\% \mathrm{CD}^{+}$cells were not changed by stimulation in vitro, the increase of $\mathrm{CD} 4 / \mathrm{CD} 8$ ratio appeared to depend on the loss of $\mathrm{CD}^{+}$cells or the increase of $\mathrm{CD} 4^{-} \mathrm{CD} 8^{-} \mathrm{T}$ cells. Although the exact reason for these phenotypical changes remained unclear, the loss of $\mathrm{CD}^{+} \mathrm{T}$ cells, which are known to work as suppressor cells in certain circumstances, ${ }^{24}{ }^{25}$ may break suppression of the development of EC. As expected, stimulation upregulated the expression of CD25, I-A, ICAM-1 (Table 3). These molecules proved to be directly involved in the induction of experimental diseases such as EAU, because injection of monoclonal antibodies against these molecules inhibited the development of EAU. ${ }^{26-29}$ Therefore, it is suspected that these molecules are also involved in the development of EC. It is obviously necessary to block these molecules by monoclonal antibodies to prove their roles in the development of EC.

IFN- $\gamma$ and IL- 4 are known as key cytokines to modulate the immune reaction towards either cellular or humoral responses. These two cytokines are usually measured for analysis of involvement of the cellular and humoral immunity mediated by $\mathrm{T}$ cells. Because reliable rat IL-4 ELISA has not been available so far, we were unable to test IL- 4 production in the 
culture supernatant of OVA primed lymph node cells with stimulation in vitro. Therefore, to investigate cytokine production by OVA primed lymph node cells, we tested both ELISA and RT-PCR. Stimulation in vitro induced IFN- $\gamma$ production, while it downregulated IL-4 gene transcription (Table 2, Fig 3). Although these data should be interpreted with caution since the conditions in which the PCR was performed may not yield quantitative data, it is suspected that our culture system promoted OVA primed lymph node cells toward Th1 type dominant cells. To determine the direct involvement of cytokines on the development of disease, treatment with monoclonal antibodies against cytokines and/or cytokine receptors in vivo, which were reported in other systems, ${ }^{30-32}$ is crucial.

In conclusion, stimulation in vitro of OVA primed lymph node cells upregulated the CD4/CD8 ratio and cell surface expression of CD25, I-A molecules on them. It also induced IFN- $\gamma$ production and stopped the expression of mRNA of IL-4. These changes as well as upregulation of antigen specificity are possibly involved in the augmentation of EC by the adoptive transfer. These results further support our previous report that cell mediated immunity was dominantly involved in the development of EC.

We would like to thank Ms Natsuko Naruoka for her technical help in the preparation of histological slides.

1 Fukushima A, Yoshida $\mathrm{H}$, Iwamoto $\mathrm{H}$, et al. The role of cellular immunity both in the induction and effector phases of experimental allergic blepharoconjunctivitis (EAC) in rats. Exp Eye Res 1997;65:631-7.

2 Pettinelli CB, McFarlin DE. Adoptive transfer of experimental allergic encephalomyelitis in SJL/J mice after in vitro activation of lymph node cells by myelin basic protein:requirement for Lyt $1+2-\mathrm{T}$ lymphocytes. $\mathcal{F}$ Immunol 1981;127:1420-3.

3 Kennedy MK, Torrance DS, Picha KS, et al. Analysis of cytokine mRNA expression in the central nervous system of mice with experimental autoimmune encephalomyelitis reveals that IL-10 mRNA expression correlates with recovery. F Immunol 1992;149:2496-505.

4 Mochizuki M, Kuwabara T, McAllister C, et al. Adoptive transfer of experimental autoimmune uveoretinitis in rats: immunopathogenic mechanisms and histologic features. Invest Ophthalmol Vis Sci 1985;26:1-9.

5 Caspi RR, Roberge FG, McAllister CG, et al. T cell lines mediating experimental autoimmune uveoretinitis (EAU) in the rat. I Immunol 1986;136:928-33.

6 Lai JC, Wawrousek EF, Lee RS, et al. Intraocular inflammation in transgenic mice expressing a foreign antigen in their lens. Ocular Immunol Inflamm 1995;3:59-62.

7 Pingel JT, Thomas ML. Evidence that the leukocytecommon antigen is required for antigen-induced $\mathrm{T}$ lymphocyte proliferation. Cell 1989;58:1055-65.

8 Janeway CA Jr. The T cell receptor as a multicomponent signalling machine: CD4/CD8 coreceptors and CD45 in T cell activation. Annu Rev Immunol 1992;10:645-74.

9 Hogg N, Landis RC. Adhesion molecules in cell interactions. Curr Opin Immunol 1993;5:383-90.

10 Hynes RO, Lander AD. Contact and adhesive specificities in the associations, migrations and targeting of cells and axons. Cell 1992;68:303-22.
11 Stout RD, Bottomly K. Antigen-specific activation of effector macrophages by IFN-gamma producing (TH1) T cell clones. Failure of IL-4-producing (TH2) T cell clones to activate effector function in macrophages. F Immunol 1989; 142:760-5.

12 Trinchieri G. Interleukin-12: a proinflammatory cytokine with immunoregulatory functions that bridge innate resistance and antigen-specific adaptive immunity. Anпu Rev Immunol 1995;13:251-76.

13 June $\mathrm{CH}$, Ledbetter JA, Lindsten T, et al. Evidence for the involvement of three distinct signals in the induction of IL-2 gene expression in human T lymphocytes. F Immunol 1989;143:153-61.

14 Minami Y, Kono T, Miyazaki T, et al. The IL-2 receptor complex: its structure, function and target genes. Annu Rev Immunol 1993;11:245-68.

15 Dustin ML, Springer TA. T-cell receptor cross-linking transiently stimulates adhesiveness through LFA-1. Nature 1989;341:619-24

16 Geiger K, Howes E, Gallina M, et al. Transgenic mice expressing IFN- $\gamma$ in the retinal develop inflammation of the eye and photoreceptor loss. Invest Ophthalmol Vis Sci 1994; 35:2667-81.

17 Von Herrath MG, Oldstone MB. Interferon- $\gamma$ is essential for destruction of beta cells and development of insulindependent diabetes mellitus. 7 Exp Med 1997;185:531-9.

18 Racke MK, Burnett D, Pak SH, et al. Retinoid treatment of experimental allergic encephalomyelitis. IL-4 production correlates with improved disease course. F Immunol 1995; 154:450-8.

19 Racke MK, Bonomo A, Scott DE, et al. Cytokine-induced immune deviation as a therapy for inflammatory autoimmune disease. $\mathcal{F}$ Exp Med 1994;180:1961-6.

20 Gleich GJ. The late phase of the immunoglobulin E-mediated reaction: a link between anaphylaxis and common allergic disease?. F Allergy Clin Immunol 1982;70:160-

21 Chomczynski P, Sacchi N. Single-step method of RNA isolation by acid guanidinium thiocyanate-phenol-chloroform extraction. Anal Biochem 1987;162:156-9.

22 Metz DP, Bacon AS, Holgate S, et al. Phenotypic characterization of $\mathrm{T}$ cells infiltrating the conjunctiva in
chronic allergic eye disease. $\mathcal{f}$ Allergy Clin Immunol 1996;98:686-96.

23 Abu el-Asrar AM, Van den Oord JJ, Geboes K, et al. Immunopathological study of vernal keratoconjunctivitis. Graefes Arch Clin Exp Ophthalmol 1989;227:374-9.

24 Ito S, Ueno M, Nishi S, Arakawa M, et al. Suppression of spontaneous murine lupus by inducing graft-versus-host reaction with $\mathrm{CD}^{+}$cells. Clin Exp Immunol 1992;90:2605.

25 Mukasa A, Itoh M, Tokunaga Y, et al. Inhibition of a novel model of murine experimental autoimmune orchitis by intravenous administration with a soluble testicular intravenous administration with a soluble testicular Immunol Immunopathol 1992;62:210-9.

26 Wetzig R, Hooks JJ, Percopo CM, et al. Anti-Ia antibody diminishes ocular inflammation in experimental autoimmune uveitis. Curr Eye Res 1988;7:809-18.

27 Kelly JD, Fox LM, Lange CF, et al. Experimental autoimmune pinealitis in the rat: ultrastructure and quantitative immunocytochemical characterization of mononuclear infiltrate and MHC class II expression. Autoimmunity 1993;16:1-11.

28 Whitcup SM, DeBarge LR, Caspi RR, et al. Monoclonal antibodies against ICAM-1 (CD54) and LFA-1 (CD11a/ CD18) inhibit experimental autoimmune uveitis. Clin Immunol Immunopathol 1993;67:143-50.

29 Uchio E, Kijima M, Tanaka S, et al. Suppression of experimental uveitis with monoclonal antibodies to ICAM-1 and LFA-1. Invest Ophthalmol Vis Sci 1994;35:2626-31.

30 Issazadeh S, Lorentzen JC, Mustafa MI, et al. Cytokines in relapsing experimental autoimmune encephalomyelitis in DA rats: persistent mRNA expression of proinflammatory cytokines and absent expression of interleukin-10 and transforming growth factor-beta. F Neuroimmunol 1996;69: 103-15.

31 Higuchi $\mathrm{M}$, Diamantstein $\mathrm{T}$, Osawa $\mathrm{H}$, et al. Combined anti-interleukin-2 receptor and low-dose cyclosporine therapy in experimental autoimmune uveoretinitis. $\mathcal{F}$ Autoimmunity 1991;4:113-24.

32 Yokoi H, Kato K, Kezuka T, et al. Prevention of experimental autoimmune uveoretinitis by monoclonal antibody to interleukin-12. Eur f Immunol 1997;27:641-6. 